\title{
Morphemes in their place: Evidence for position-specific identification of suffixes
}

\author{
Davide Crepaldi \\ University of Milano-Bicocca, Milan, Italy \\ AND \\ Kathleen Rastle and Colin J. Davis \\ Royal Holloway, University of London, London, England
}

\begin{abstract}
Previous research strongly suggests that morphologically complex words are recognized in terms of their constituent morphemes. A question thus arises as to how the recognition system codes for morpheme position within words, given that it needs to distinguish morphological anagrams like overhang and hangover. The present study focused specifically on whether the recognition of suffixes occurs in a position-specific fashion. Experiments 1 and 2 revealed that morphologically complex nonwords ( $g a s f u l$ ) are rejected more slowly than orthographic controls (gasfil) but that the same interference effect is not present when the morphemic constituents are reversed ( fulgas vs. filgas). Experiment 3 went further in demonstrating that reversing the morphemes within words (e.g., nesskind) does not yield morpheme interference effects against orthographic controls (e.g., nusskind). These results strongly suggest that suffix identification is position specific, which imposes important constraints on the further development of models of morphological processing.
\end{abstract}

Previous research on the identification of morphologically complex words like player has established that such words are decomposed into their constituent morphemes (i.e., play + er) during recognition. Evidence for decomposition comes largely from the findings that (1) the time taken to recognize a morphologically complex word is partly determined by the frequency of its stem (e.g., Baayen, Dijkstra, \& Schreuder, 1997; Bradley, 1980; New, Brysbaert, Segui, Ferrand, \& Rastle, 2004) and (2) the recognition of stem targets is speeded by the prior brief presentation of morphologically related words (e.g., Drews \& Zwitserlood, 1995; Grainger, Colé, \& Segui, 1991; Rastle, Davis, MarslenWilson, \& Tyler, 2000) more than would be expected on the basis of pure orthographic or semantic overlap.

Another well-described phenomenon used to investigate morpheme recognition is the morpheme interference effect on nonword rejection times. This effect refers to the finding that nonwords comprising existing morphemes (e.g., shootment) are rejected more slowly in lexical decision than are nonwords that do not have a morphological structure (e.g., shootmant). This result was first reported by Taft and Forster (1975), who found that nonwords composed of existing prefixes and bound stems (e.g., dejuvenate) were rejected more slowly than were nonwords composed of the same prefixes but nonexisting stems (e.g., depertoire). Caramazza, Laudanna, and Romani (1988) went on to show that Italian pseudoinflected nonwords comprising existing stems and suffixes (e.g., cant-evi, similar to buyed in English) were rejected more slowly and elicited higher error rates than did (1) nonwords comprising stems plus a nonsuffix endings (e.g., cant-ovi, buyel), (2) nonwords comprising nonstems plus suffix endings (e.g., canz-evi, biyed), and (3) nonwords comprising nonstems plus nonsuffix endings (e.g., canz-ovi, biyel). The usual explanation for this effect is that morphemic representations are activated during the processing of morphologically structured nonwords, thus slowing rejection time (Caramazza et al., 1988). In contrast to some recent models claiming that morphological processing is a postlexical phenomenon (e.g., Giraudo \& Grainger, 2001), the morpheme interference effect suggests strongly that morphemic representations are activated prior to the activation of orthographic lexical entries (see also Kazanina, Dukova-Zheleva, Geber, Kharlamov, \& Tonciulescu, 2008; Longtin, Segui, \& Hallé, 2003; Marslen-Wilson, Bozic, \& Randall, 2008; Rastle, Davis, \& New, 2004; Taft, 1994).

Evidence that morphologically complex words are recognized through a process of decomposition that takes place prior to the activation of orthographic lexical entries raises an important theoretical issue that has largely gone unnoticed in psycholinguistic research. Specifically, how is it that we are able to distinguish between morphologically complex stimuli comprising the same morphemes but in reversed order (e.g., preheat vs. heatpre)? This question relates to a more general issue about the code used by the word recognition system to represent morpheme position: Does this code allow morphemes to be recognized independently of their positions, or is their recognition dependent on their surrounding context? The related issue of

D. Crepaldi, davide.crepaldi1@unimib.it 
letter position coding has been the subject of fairly intense study in recent years, and here the evidence favors models that assume position-invariant letter representations (for reviews, see Davis, 2006; Grainger, 2008). Intuitively, one might expect that morpheme representations should also be position invariant; otherwise, the -ness in kindness would be different from the -ness in aimlessness. However, it could be the case that the recognition of affixes is dependent on their position relative to stems (e.g., -ness would be recognized only if it occurred after a stem).

Some evidence pertaining to this question has been obtained in Chinese. For example, Taft, Zhu, and Peng (1999) reported slower recognition times for transposable Chinese compounds - that is, bimorphemic words whose morphemes could be transposed to form another complex word (something comparable to the English example hangover, which shares the same constituent morphemes as the word overhang). These results were interpreted in terms of interference between words sharing morphemes in different positions and were thus taken as indicating some degree of position invariance in morphological representations. However, there are several factors hampering a direct generalization of these results to other languages. Chinese uses a syllabic script, in which single characters correspond to syllables rather than phonemes; this script most likely requires a rather different functional organization of the word recognition system than in English (e.g., Taft et al., 1999). Moreover, unlike English and other Western languages, the Chinese morphological system is heavily based on compounding, with a complete absence of derivation and inflection. Thus, it is difficult to use this evidence to settle the question of whether English morphemes are represented in a position-specific or a position-invariant manner.

Nevertheless, some evidence has been obtained in English that parallels the results described by Taft et al. (1999) in Chinese. Taft (1985) reported that reversed compounds (e.g., stooltoad) are more difficult to reject in a lexical decision task than are ordinary compound nonwords (e.g., tallmop). Reversed compounds have also been shown to elicit longer rejection times than have compound nonwords, including semantically related morphemes, like fastslow (Shoolman \& Andrews, 2003). Unfortunately, though, neither of these experiments included orthographic controls for the reversed compounds, thus making it difficult to determine whether they indicate a morphological or a purely orthographic effect (e.g., that stooltoad is more similar to an existing word - i.e., toadstool - than is tallmop).

In the present work, we begin to consider the issue of morpheme position coding by using the morpheme interference effect to investigate whether morphemes in the "wrong" position activate lexical representations during word recognition. Specifically, we tested whether suffixes are accessed by the word recognition system when they occur at nonword onset (e.g., nesstrue), thus yielding a processing disadvantage, relative to matched nonwords without a morphological structure (e.g., nelstrue). Experiment 1 thus comprised four conditions. The first two conditions included morphologically structured nonwords (e.g., gasful) and their matched orthographic controls (e.g., gasfil), whereas the final two conditions consisted of these stimuli with the morphemes reversed (e.g., fulgas and filgas). If suffixes are recognized by skilled readers independently of their position, we should observe equivalent interference from the gasful and fulgas stimuli, relative to their orthographic controls. If, instead, suffix representations are position specific, suffixes should not be recognized when occurring at nonword onset; in this case, we would not expect the fulgas stimuli to yield an interference effect, relative to their orthographic controls.

\section{EXPERIMENT 1}

\section{Method}

Participants. Forty-seven undergraduate students at Royal Holloway, University of London, participated in the experiment; all were native speakers of English and had no history of learning disabilities and/or neurological impairment. The participants were given $£ 5$ in exchange for their time.

Materials. The experimental stimulus set comprised four groups of 64 nonwords. In the stem-plus-suffix condition, existing stems were combined with existing suffixes (e.g., gasful). These combinations were always syntactically legal; that is, suffixes were attached to stems belonging to the grammatical class that they normally modify (e.g., -ful was attached only to nouns, as in peaceful, or to verbs, as in forgetful). Nonwords in this condition were constructed by using 16 different suffixes, each of which was attached to four different stems. We did not include in the stimulus set suffixes that (1) were homographic with existing words (e.g., -ant), (2) were most frequently used as inflections (e.g., -ed), (3) often resulted in allomorphic changes of the stem (e.g., -ion), or (4) were one letter long (e.g., y). In the stem-plus-control condition, the same stems were combined with nonmorphological endings that were orthographically similar to the suffixes used in the stem-plus-suffix condition (e.g., gasfil). Nonmorphological endings were created by changing one letter of each of the suffixes used in the first condition; if possible (i.e., in three- and four-letter-long suffixes), the change was made in a central position, so as to make sure that the letters lying at the morphemic boundary remained the same. Items in the suffix-plus-stem condition were created by reversing the order of the two constituents of items from the stem-plus-suffix condition (e.g., fulgas). Likewise, items in the control-plus-stem condition were created by reversing the order of the two constituents of items from the stem-plus-control condition (e.g., filgas). The complete list of nonword stimuli used in Experiment 1 is provided in Appendix A.

The use of the same morphemes across conditions ensured pairwise matching for stem and suffix frequency and also ensured that the nonwords in the four conditions were matched with respect to number of letters. The suffix conditions were also matched listwise with the control conditions with respect to number of syllables (see Table 1). Because morphemes also constitute frequently occurring clusters of letters (as opposed to their nonmorphological counterparts), it was impossible to match mean log bigram frequency (MLBF) between the suffix and control conditions. However, we ensured that the difference in MLBF between the suffix and control conditions did not vary as a function of whether the suffix occurred in the initial or final position of the nonwords. We reasoned that, should a morpheme interference effect emerge only when morphemes occupy their usual positions (e.g., gasful vs. gasfil), this matching of MLBF differences across position conditions would allow us to conclude that MLBF was not sufficient to explain the observed results. Care was also taken to guarantee that the nonwords in the four conditions were matched with respect to measures of their orthographic similarity to existing words. Thus, the suffix and control conditions were closely matched with respect to number of orthographic neighbors, as well as their mean orthographic Levenshtein distance (i.e., edit distance) to the nearest word neighbor (Yarkoni, Balota, \& Yap, 2008).

Since the same morphemes were used across conditions, the experimental nonwords were distributed over four different rotations, 
Table 1

General Characteristics of the Stimuli Used in Experiment 1

\begin{tabular}{|c|c|c|c|c|c|c|c|c|}
\hline & \multicolumn{2}{|c|}{$\begin{array}{l}\text { Stem-Plus- } \\
\text { Suffix } \\
\text { (e.g., gasful) }\end{array}$} & \multicolumn{2}{|c|}{$\begin{array}{l}\text { Stem-Plus- } \\
\text { Control } \\
\text { (e.g., gasfil) }\end{array}$} & \multicolumn{2}{|c|}{$\begin{array}{l}\text { Suffix-Plus- } \\
\text { Stem } \\
\text { (e.g., fulgas) }\end{array}$} & \multicolumn{2}{|c|}{$\begin{array}{c}\text { Control- } \\
\text { Plus-Stem } \\
\text { (e.g., filgas) } \\
\end{array}$} \\
\hline & $M$ & $S D$ & $M$ & $S D$ & $M$ & $S D$ & $M$ & $S D$ \\
\hline Sy & 2.36 & 0.48 & 2.34 & 0.48 & 2.48 & 0.50 & 2.50 & 0.50 \\
\hline MLBF & 2.41 & 0.34 & 2.25 & 0.38 & 1.75 & 0.43 & 1.71 & 0.45 \\
\hline$N$ & 0.19 & 0.62 & 0.03 & 0.18 & 0.03 & 0.18 & 0.03 & 0.18 \\
\hline OLD1 & 1.95 & 0.49 & 2.04 & 0.52 & 2.40 & 0.66 & 2.50 & 0.67 \\
\hline
\end{tabular}

Note-Syll, number of syllables; MLBF, mean logarithmic bigram frequency; $N$, number of orthographic neighbors; OLD1, orthographic Levenshtein distance to the nearest word neighbor.

each of which included 16 items per condition. This design also ensured that no participant saw (1) the same stem or (2) the same suffix in the same position twice.

Sixty-four morphologically complex words, 56 simple words, and 56 simple nonwords (obtained by changing one or two letters from existing monomorphemic words) served as filler trials in this study, thus ensuring that (1) each version of the experiment had the same number of word and nonword trials and (2) the overall proportion of morphologically (pseudo)complex stimuli (.53) was not too high. Filler stimuli were comparable to the experimental items with respect to length in letters, number of syllables, MLBF, and orthographic neighborhood size $(N)$.

Procedure. The participants were tested in a dimly lit room and were instructed to decide whether or not the letter strings appearing on the screen were existing English words. The participants were given eight practice trials to familiarize themselves with the task, and each experimental session began with six warm-up filler trials that were not analyzed.

The trials started with a fixation cross presented at the center of the screen for $500 \mathrm{msec}$; the uppercase target string on which the participant had to make a lexical decision immediately followed. The target string remained on the screen until the participant's response. There was a 1-sec interstimulus interval between trials.

Stimulus presentation and data recording were controlled by the DMDX software (Forster \& Forster, 2003). A two-button response box was used to record lexical decisions, with the button corresponding to a yes response being controlled by the participant's dominant hand.

Trial presentation within lists was pseudorandomized, so that no more than eight word or nonword targets could occur in a row; this design also ensured that no more than four experimental items were presented on 15 consecutive trials.

\section{Results}

Outliers were removed according to the following procedure. Items were excluded from the analyses if they elicited (1) an overall error rate higher than $15 \%$ or (2) an average response time (RT) more than two standard deviations higher than the overall nonword mean. Similarly, participants were excluded if (1) their overall error rate on word or nonword trials was higher than $15 \%$ or (2) their mean RT on word or nonword trials was more than two standard deviations higher than the relevant mean RT for all the participants. Finally, individual RTs that were exceptionally long (lying over the first zero of their density function, which was $1,800 \mathrm{msec}$ in this experiment) were also excluded. This procedure resulted in the exclusion of 12 items, 2 participants, and seven individual data points.

The remaining data were analyzed through byparticipant and by-item ANOVAs that treated morphological structure (stem-plus-suffix vs. stem-plus-control) and morpheme position (initial vs. final) as repeated factors and rotation (four versions) as an unrepeated factor. The ANOVA was carried out on inverse-transformed RTs so as to increase the normality of the RT distribution (Ulrich \& Miller, 1994).

The mean RT and error rate for word stimuli were $677 \mathrm{msec}$ and .06, respectively. The mean RTs and error rates obtained by the participants in the four nonword conditions are reported in Table 2. The ANOVA carried out on the RT data revealed an effect of morphological structure $\left[F_{1}(1,41)=8.40, p<.01 ; F_{2}(1,57)=6.71, p=\right.$ $.01]$, an effect of morpheme position $\left[F_{1}(1,41)=122.38\right.$, $\left.p<.001 ; F_{2}(1,57)=78.33, p<.001\right]$, and, critically, an interaction between the two factors $\left[F_{1}(1,41)=35.47\right.$, $\left.p<.001 ; F_{2}(1,57)=13.71, p<.001\right]$. This significant interaction reflects the fact that the morpheme interference effect was present when morphemes occupied their usual positions (i.e., the suffix was in the final position, as in gasful) $\left[t_{1}(44)=5.81, p<.001 ; t_{2}(60)=3.90, p<\right.$ $.001]$ but was absent when the order of morphemes was reversed (as in fulgas) $\left[t_{1}(44)=-0.95, p=.34 ; t_{2}(60)=\right.$ $0.81, p=.42]$.

These results are perfectly mirrored in the ANOVA carried out on error rates. The main effects of both morphological structure $\left[F_{1}(1,41)=45.75, p<.001 ; F_{2}(1,57)=\right.$ $12.09, p=.001]$ and morpheme position $\left[F_{1}(1,41)=50.46\right.$, $\left.p<.001 ; F_{2}(1,57)=48.80, p<.001\right]$ were significant, as was the interaction between these factors $\left[F_{1}(1,41)=\right.$ $\left.35.06, p<.001 ; F_{2}(1,57)=13.30, p=.001\right]$. This interaction arose from a strong morpheme interference ef-

Table 2

Response Times (RTs, in Milliseconds) and Error Rates in Experiments 1 and 2

\begin{tabular}{|c|c|c|c|c|c|c|c|c|}
\hline & \multicolumn{2}{|c|}{$\begin{array}{l}\text { Stem-Plus- } \\
\quad \text { Suffix } \\
\text { (e.g., gasful) }\end{array}$} & \multicolumn{2}{|c|}{$\begin{array}{c}\text { Stem-Plus- } \\
\text { Control } \\
\text { (e.g., gasfil) } \\
\end{array}$} & \multicolumn{2}{|c|}{$\begin{array}{l}\text { Suffix-Plus- } \\
\text { Stem } \\
\text { (e.g., fulgas) } \\
\end{array}$} & \multicolumn{2}{|c|}{$\begin{array}{c}\text { Control- } \\
\text { Plus-Stem } \\
\text { (e.g., filgas) } \\
\end{array}$} \\
\hline & $M$ & $S D$ & $M$ & $S D$ & $M$ & $S D$ & $M$ & $S D$ \\
\hline \multicolumn{9}{|l|}{ Experiment 1} \\
\hline RT & 782 & 175 & 724 & 163 & 667 & 155 & 675 & 147 \\
\hline Error rate & .11 & .09 & .03 & .06 & .01 & .02 & .01 & .02 \\
\hline \multicolumn{9}{|l|}{ Experiment 2} \\
\hline RT & 732 & 120 & 686 & 120 & 639 & 101 & 638 & 115 \\
\hline Error rate & .07 & .08 & .02 & .04 & .01 & .04 & .01 & .04 \\
\hline
\end{tabular}


fect when the morphemes occupied their usual positions $\left[t_{1}(44)=6.20, p<.001 ; t_{2}(60)=3.39, p=.001\right]$ and $a$ complete lack of effect when the order of the morphemes was reversed $\left[t_{1}(44)=0.00, p=1 ; t_{2}(60)=0.00, p=1\right]$.

Following a reviewer's suggestion, we performed further post hoc analyses in order to test an alternative explanation of the absence of any interference effect in the suffix-plus-stem condition. Specifically, there were a number of control-plus-stem items that began with an existing prefix or stem-namely, mant (which includes man), enge (which includes en-, as in entrust), ilm and ilt (which include il-, as in illogical), ady (which includes $a d-$, as in adjoin), and ime (which includes im-, as in imprudent). It is possible that the presence of these units at the start of the nonword could have increased the difficulty of these items, thereby washing out any interference effect that might have emerged in the suffix-plus-stem versus control-plus-stem conditions. The role played by this possible confounding factor was checked post hoc in two ways. First, two new ANOVAs were run on inversetransformed RTs and on error rates that included, as an additional factor, the presence of an existing morpheme at the onset of the control-plus-stem items. These analyses confirmed the existence of an interaction between morphological structure and morpheme position [RT analysis, $F_{2}(1,59)=7.56, p=.008$; error rate analysis, $\left.F_{2}(1,59)=10.58, p=.002\right]$, and also showed that this effect was insensitive to the presence of an existing morpheme at the onset of the control-plus-stem items [thirdlevel interaction; RT analysis, $F_{2}(1,59)=1.74, p=.19$; error rate analysis, $\left.F_{2}(1,59)=1.19, p=.28\right]$. Since the possible confounding factor only affected the suffix-plusstem and the control-plus-stem conditions, its impact on the results of Experiment 1 was also checked by dividing the stimulus set according to whether the control-plusstem nonwords started with an existing morpheme. Analyses on the resulting subsets showed equivalent results; that is, there was no evidence of an interference effect when suffix-plus-stem and control-plus-stem items were compared, irrespective of whether the latter nonwords contained an initial morpheme [e.g., arytrip vs. adytrip; RT analysis, $t_{2}(22)=0.30, p=.77$; error rate analysis, $t_{2}(22)=0.64, p=.53$ ] or not [e.g., fulgas vs. filgas; RT analysis, $t_{2}(37)=0.647, p=.52$; error rate analysis, $\left.t_{2}(37)=0.49, p=.62\right]$.

\section{Discussion}

The results of Experiment 1 reveal that legal combinations of existing stems and existing suffixes (e.g., gasful) elicit longer RTs than do nonwords including the same stems and nonmorphological endings (e.g., gasfil). This finding demonstrates that the morpheme interference effect previously reported by Taft and Forster (1975) for pseudoprefixed English nonwords with bound stems and by Caramazza et al. (1988) for pseudoinflected Italian nonwords also generalizes to pseudosuffixed English nonwords. These results can be most immediately interpreted as reflecting the ability of the word recognition system to access morpheme representations in nonword stimuli; since gasful activates the representations of both gas and ful, it takes longer for the system to reject it, as compared with gasfil, which instead activates only gas, but no other morphemes.

Crucially, the same effect does not emerge when suffixes are shifted to the initial position; for example, fulgas was no more difficult to reject than filgas. The difference between the morphological nonwords and their orthographic controls was comparable in the scrambled- and unscrambledmorpheme conditions for potentially relevant factors such as length, stem frequency, and mean bigram frequency. It seems reasonable to conclude, then, that derivational suffixes were not recognized at the onsets of nonwords.

However, there is an alternative explanation of the present results that warrants consideration. Specifically, a number of the suffixes used in Experiment 1 may look relatively unusual when they occur in the initial position (e.g., itypoor), meaning that nonwords in the suffix-initial conditions may have been less wordlike than the nonwords in the suffix-final conditions. This aspect of the stimuli may have allowed the participants to reject the former nonwords relatively rapidly, with little lexical (or morphological) processing.

Experiment 2 was designed to address this possibility. We replicated Experiment 1, using a new set of filler words that were selected to be just as orthographically unusual as the suffix-initial nonwords. We reasoned that the inclusion of such fillers would prevent the participants in Experiment 2 from rejecting suffix-initial nonwords purely on the basis of their low orthographic plausibility as existing words (since such a strategy would also lead to very high rejection rates for the filler word stimuli).

\section{EXPERIMENT 2}

In Experiment 2, we tested the same four experimental conditions as those included in Experiment 1 (e.g., stimulus quadruples like gumful, gumfil, fulgum, and filgum), using the same set of stimuli. However, the filler words included in the previous experiment were replaced with a different set of words that were selected to be relatively orthographically unusual (e.g., hyena, sphinx, euphoria). Specifically, these filler words were of very low bigram frequency, and their mean orthographic neighborhood size was 0 . If the absence of interference for suffix-plus-stem nonwords in Experiment 1 was due to the fact that suffixes occurring in the initial position did not automatically activate suffix representations, a similar pattern of results should be obtained in Experiment 2.

\section{Method}

Participants. Thirty-eight participants from the same population as that in Experiment 1 volunteered for this experiment. None of the participants had been included in Experiment 1.

Materials and Procedure. The stimulus materials used in this experiment were identical to those used in Experiment 1, except that the monomorphemic filler words used in that experiment were replaced by a new set of monomorphemic words (see Appendix B). The new fillers were comparable to those used in Experiment 1 with respect to length and number of syllables but were much lower with respect to orthographic wordlikeness measures such as MLBF and orthographic neighborhood size (MLBF, $1.87 \pm 0.37 ; N, 0.09 \pm$ 0.29 ), so that they were now matched on these variables with stimuli 
in the suffix-initial nonword condition (see Table 1). This matching ensured that orthographic wordlikeness could not be used as a reliable basis for participants' lexical decisions.

\section{Results}

Outliers were excluded from further analyses, following the same procedure as that used in Experiment 1, resulting in the exclusion of four items, 5 participants, and five individual data points (those that were higher than $1,800 \mathrm{msec}$ ).

The mean RT and error rate for word stimuli were $681 \mathrm{msec}$ and .08, respectively; importantly, the participants did not experience particular problems with the orthographically implausible words (their mean RT on these stimuli was $694 \mathrm{msec}$, and their mean error rate was .10). By-participant and by-item analyses on the nonword data were conducted in the same way as in Experiment 1; mean RTs and error rates in the different experimental conditions are reported in Table 2. The RT analysis showed exactly the same pattern of results as in Experiment 1. There were significant main effects of morphological structure $\left[F_{1}(1,29)=14.52, p=.001 ; F_{2}(1,59)=7.19, p=.01\right]$ and morpheme position $\left[F_{1}(1,29)=94.73, p<.001\right.$; $\left.F_{2}(1,59)=62.60, p<.001\right]$ and an interaction between these two factors $\left[F_{1}(1,29)=12.27, p<.005 ; F_{2}(1,59)=\right.$ $8.93, p<.005]$. This interaction reflected a significant morpheme interference effect when suffixes occupied the final position $\left[t_{1}(32)=6.15, p<.001 ; t_{2}(62)=3.09, p<\right.$ $.005]$ but no morpheme interference effect when the suffixes occupied the initial position $\left[t_{1}(32)=0.02, p=.92\right.$; $\left.t_{2}(62)=0.24, p=.81\right]$.

The analysis of errors also revealed main effects of morphological structure $\left[F_{1}(1,29)=10.45, p=.003 ; F_{2}(1,59)=\right.$ $3.61, p=.06]$ and morpheme position $\left[F_{1}(1,29)=16.26\right.$, $\left.p<.001 ; F_{2}(1,59)=24.01, p<.001\right]$, and an interaction between these two factors $\left[F_{1}(1,29)=8.63, p<.01\right.$; $\left.F_{2}(1,59)=5.14, p<.05\right]$. Once again, the interaction reflected a significant morpheme interference effect when suffixes occupied the final position $\left[t_{1}(32)=3.39, p<.005\right.$; $\left.t_{2}(62)=2.30, p=.02\right]$, but no morpheme interference effect when suffixes occupied the initial position $\left[t_{1}(32)=0.63\right.$, $\left.p=.53 ; t_{2}(62)=-0.43, p=.67\right] .^{1}$

\section{Discussion}

The results of Experiment 2 perfectly replicated those obtained in Experiment 1. Pseudoderived nonwords made up of an existing stem followed by an existing suffix (e.g., gumful) were rejected more slowly than nonwords that included the same stems and nonmorphological endings (e.g., gumfil). This interference effect was not observed when the same morphemes appeared in reversed order: Nonwords like fulgum and filgum elicited equivalent rejection times. As was noted earlier, the absence of any morpheme interference effect for suffix-initial nonwords in Experiment 1 could have conceivably been attributed to the orthographic atypicality of these nonwords (such that it was possible to classify these nonwords without engaging in morphological/lexical processing). However, the results of the present experiment allow us to reject this explanation. If the participants had classified stimuli purely on the basis of their orthographic structure, they would have misclassified the filler words like apocalypse. The data showed no indication that the participants were following such a strategy. Having ruled out the possibility that nonwords like fulgum and filgum were rejected solely on the basis of their infrequent orthographic appearance, these results clearly suggest that suffix representations are not accessed by the word recognition system when they occur at the beginning of a letter string - that is, in a position that they never occupy in existing words.

One attempt to rescue the theoretical possibility of position-invariant suffix recognition might be to argue that nonword interference effects in the lexical decision task reflect the activation, not of morphemic representations, but of lexical representations, and that suffix-initial nonwords are simply not very effective at activating these representations. Suffix representations in the word recognition system may be activated and coded for position whenever suffixes occur within letter strings (irrespective of their position), but suffixes that are coded as occupying the initial position are not very effective at activating lexical representations, because there are no words that begin with suffixes. For example, a nonword like nesslong might weakly activate the lexical representations for goodness, greatness, or baldness, but the nonword longness will activate these same representations far more strongly because -ness occupies the same position and, therefore, provides a closer match to these words. Perhaps, then, if a more sensitive test of morpheme activation were available, it might be determined that suffix representations are partially activated by suffix-initial nonwords. The aim of Experiment 3 was to test this account by increasing the sensitivity with which morpheme interference effects might be detected.

\section{EXPERIMENT 3}

The final experiment we report was designed to provide one more opportunity to observe evidence for the activation of suffix representations in suffix-initial stimuli, in an experimental situation that optimized the opportunity for detecting morpheme interference effects. To do this, we examined responses to suffix-initial nonwords like nesskind that were formed by transposing the morphemes in existing suffixed words (i.e., kindness). If the morphemic representations for both ness and kind are partially activated, it seems plausible that their conjoint activation could result in the activation of the word representation for kindness, resulting in relatively slow and error-prone rejections of the nonword nesskind.

As we have reported in the introduction, there is already some evidence that nonwords formed by transposing morphemes are particularly hard to reject. Both Taft (1985) and Shoolman and Andrews (2003) reported data on the difficulty of rejecting compounds with transposed constituents (e.g., walkjay, berryblack), although these experiments did not include orthographic control conditions of the sort that we have used. It is also important to note that compounds include free morphemes, which are not directly comparable to suffixes, since the same free morpheme can occur in either a word-initial (e.g., overload) or 
a word-final (e.g., hangover) position. Nevertheless, these data suggest that the activation of morphemic constituents can, in turn, activate lexical representations even when the morphemes occupy the incorrect position. Thus, if the suffix representation of ness is even partly activated when it occurs in word-initial position, it seems reasonable to expect that nesskind will result in activation of the lexical representation for kindness (in much the same way that jugde can result in the activation of the lexical representation for judge; e.g., Perea \& Lupker, 2003). This activation should then lead to rejection latencies longer than those for orthographic controls like nusskind.

Of course, a difference in response latencies between nonwords like nesskind and nusskind could be attributed to pure orthographic similarity, given that nesskind is an anagram of kindness, whereas nusskind is not. To test for this possibility, we included two additional conditions in Experiment 3. Nonwords in these two conditions were constructed in the same fashion as for the critical transposedmorpheme (nesskind) and control (nusskind) stimuli, with the exception that the base words were monomorphemic. For example, the monomorphemic word attitude gave rise to the transposed-halves nonword tudeatti and its orthographic control tadeatti. Any difference between the latter two conditions would be attributed to orthographic factors. Evidence of a larger difference between nesskind and nusskind would be treated as evidence of a morphological component to the interference effect, presumably reflecting the automatic activation of suffix representations.

\section{Method}

Participants. Forty-five students participated in this experiment, drawn from the same population as in Experiments 1 and 2. None of the participants took part in either of the initial experiments.

Materials and Procedure. Experimental materials were based on 34 derived words and 34 morphologically simple words. All of the 34 derived words were made up of two morphemes (e.g., deaf-ness) and made use of 17 different suffixes (with 2 derived words for each suffix). The criteria for selecting particular suffixes were identical to those used in Experiment 1. The 34 simple words were matched to the derived words as closely as possible for length (complex, $8.09 \pm 1.44$; simple, $8.15 \pm 0.66$ ), logarithmic written frequency (complex, $0.84 \pm 0.72$; simple, $1.12 \pm 0.51$ ), and number of orthographic neighbors (complex, $0.32 \pm 0.68$; simple, $0.21 \pm 0.48)$.

The morphemes within the 34 derived words were reversed (e.g., nessdeaf ) to create the stimuli for the transposed morphemes condition. These stimuli were then altered by changing a single letter in the suffix morpheme to form matched orthographic controls (e.g., nelsdeaf ). The stimuli for the nonmorphological conditions were constructed in the same fashion, with the only difference being that the transposed halves did not correspond to morphemes. Thus, the stimuli in the transposed halves condition were created by reversing the order of the two halves of morphologically simple words (e.g., quarrel became relquar). Matched orthographic controls were constructed by changing one letter of the initial part of the transposed halves nonwords (e.g., the control for relquar was ralquar). The stimuli are listed in Appendix C.

Table 3 summarizes the characteristics of the nonwords included in the four experimental conditions. As can be seen, transposed stimuli were matched to their orthographic controls with respect to length in letters, number of syllables, MLBF, and Levenshtein distance to their nearest word neighbor. The orthographic overlap between the transposed stimuli and their base words (e.g., between deafness and
Table 3

Characteristics of the Stimuli Included in Experiment 3

\begin{tabular}{|c|c|c|c|c|c|c|c|c|}
\hline & \multicolumn{2}{|c|}{$\begin{array}{c}\text { TM } \\
\text { (e.g., } \\
\text { nessdeaf })\end{array}$} & \multicolumn{2}{|c|}{$\begin{array}{l}\text { TM Control } \\
\text { (e.g., } \\
\text { nelsdeaf) }\end{array}$} & \multicolumn{2}{|c|}{$\begin{array}{c}\text { TH } \\
\text { (e.g., } \\
\text { relquar) }\end{array}$} & \multicolumn{2}{|c|}{$\begin{array}{l}\text { TH Control } \\
\text { (e.g., } \\
\text { ralquar) }\end{array}$} \\
\hline & $M$ & $S D$ & $M$ & $S D$ & $M$ & $S D$ & $M$ & $S D$ \\
\hline & 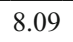 & & & & & 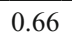 & 016 & 0.66 \\
\hline & & & & & & & & 0.51 \\
\hline & & & & & & & & 0.41 \\
\hline$D$ & & & & & & 6 & 8 & 0.76 \\
\hline & .50 & .0 & & & 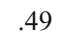 & .06 & 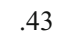 & .08 \\
\hline OObigr & .61 & .09 & .50 & .10 & .66 & .07 & .49 & .11 \\
\hline
\end{tabular}

Note-TM, transposed morphemes; TH, transposed halves; Syll, number of syllables; MLBF, mean log bigram frequency; OLD1, orthographic Levenshtein distance to the nearest word neighbor; OOspat, orthographic overlap with the reversed existing word (e.g., deafness for nessdeaf and quarrel for relquar) according to the spatial coding of letter position; OObigr, orthographic overlap with the reversed existing word according to the open bigram coding of letter position.

nessdeaf, and between quarrel and relquar) was also matched according to theoretical match values derived from spatial coding (e.g., Davis \& Bowers, 2006) and open-bigram coding (e.g., Grainger \& Whitney, 2004) models of letter position coding. This matching was intended to allow us to detect the effects of morphological similarity above and beyond those of pure orthographic similarity.

The experimental stimuli were arranged into two different versions, so that no participant saw the same suffix (or the corresponding nonmorphological ending) twice. The same filler trials as those used in Experiment 2 were also employed here; the inclusion of lowMLBF simple words ensured again that the participants could not make correct lexical decisions purely on the basis of orthographic typicality. Due to the different number of experimental stimuli included in each rotation, as compared with Experiments 1 and 2, four simple nonwords, four simple words, and four complex words were added to the final set of filler trials, so as to keep the proportion of complex stimuli constant across experiments. Filler stimuli were comparable to the experimental items for length in letters, number of syllables, MLBF, and orthographic neighborhood size.

The procedures adopted in this experiment were identical to those used in Experiments 1 and 2.

\section{Results}

Outlying data points were excluded from further analyses, following the same procedure as that used in Experiments 1 and 2; this resulted in the exclusion of two items, 6 participants, and two individual data points (those that were higher than $1,700 \mathrm{msec}$ ). The remaining data were then used to build the by-item and by-participant data sets, which were analyzed as in Experiments 1 and 2. The byparticipant analysis was based on a mixed-design ANOVA with morphological structure (complex vs. simple) and orthographic structure (anagrams vs. orthographic controls) as repeated factors and rotation as an unrepeated factor. The design was identical in the by-item analysis, except that morphological structure was modeled as an unrepeated factor.

The RTs and error rates obtained in the four experimental conditions are reported in Table 4. The ANOVA revealed no effect whatsoever in either RT or accuracy analyses [all $F$ values were lower than 1, except for the orthographic structure $F_{1}$ in the accuracy analysis; $\left.F_{1}(1,43)=1.73, p=.20\right]$. Null effects also emerged in the pairwise comparisons between the transposed condi- 
Table 4

Response Times (RTs, in Milliseconds) and Error Rates Obtained by the Participants in Experiment 3 in the Four Experimental Conditions

\begin{tabular}{|c|c|c|c|c|c|c|c|c|}
\hline & \multicolumn{2}{|c|}{$\begin{array}{c}\text { TM } \\
\text { (e.g., } \\
\text { nessdeaf) }\end{array}$} & \multicolumn{2}{|c|}{$\begin{array}{l}\text { TM Control } \\
\text { (e.g., } \\
\text { nelsdeaf) }\end{array}$} & \multicolumn{2}{|c|}{$\begin{array}{c}\text { TH } \\
\text { (e.g., } \\
\text { relquar) }\end{array}$} & \multicolumn{2}{|c|}{$\begin{array}{c}\text { TH Control } \\
\text { (e.g., } \\
\text { ralquar) }\end{array}$} \\
\hline & $M$ & $S D$ & $M$ & $S D$ & $M$ & $S D$ & $M$ & $S D$ \\
\hline & 636 & 102 & 641 & 113 & 639 & 107 & 632 & 118 \\
\hline Eror rat & .04 & .09 & .04 & .09 & .05 & .10 & .04 & 08 \\
\hline
\end{tabular}

$\begin{array}{lllllllll}\text { Error rate } & .04 & .09 & .04 & .09 & .05 & .10 & .04 & .08\end{array}$

Note-TM, transposed morphemes; TH, transposed halves.

tions and their matched orthographic controls [all $t$ values were lower than 1, except for the by-participant transposed halves vs. transposed halves control comparison in the accuracy analysis; $\left.t_{1}(44)=1.50, p=.14\right]$

\section{Discussion}

Experiment 3 was designed to test whether nonwords beginning with suffixes would exhibit a morpheme interference effect in the context of transposed morpheme nonwords like nesskind. Previous research (Shoolman \& Andrews, 2003; Taft, 1985) has suggested interference effects for nonwords formed by transposing the morphemes in compound words (e.g., droprain). It was therefore expected that the transposed morpheme nonwords in Experiment 3 would provide an even greater opportunity for morpheme interference effects to occur than in Experiments 1 and 2. However, the results showed no evidence whatsoever of a morpheme interference effect: nesskind was no more difficult to reject than nelskind, despite the fact that kindness is a familiar word. Furthermore, it is implausible to attribute the absence of morpheme interference to the orthographic similarity of suffixes and their controls (e.g., ness and nels), given that both Experiments 1 and 2 showed large morpheme interference effects based on the same suffix-control comparisons, provided that the suffix occurred in word-final position (e.g., nonwords like begness were reliably slower than nonwords like begnuss, by around $40-60 \mathrm{msec}$ ). Clearly, genuine suffixes and oneletter-different controls are sufficiently different to drive strong morpheme interference effects. The critical factor appears to be the position of the suffix unit: Suffixes in the word-final position result in large interference effects, whereas suffixes in the word-initial position produce no interference. This pattern strongly suggests that suffix representations are automatically activated when suffixes occur in the final position but do not become even partially activated when the word recognition system is presented with suffixes occurring at the initial position.

\section{GENERAL DISCUSSION}

Previous research has established that the morphemic structure of a stimulus is analyzed prior to the activation of whole-word lexical entries in visual word recognition (e.g., Caramazza et al., 1988; Longtin et al., 2003; Rastle et al., 2004; Taft \& Forster, 1975). This sublexical decomposition of morphologically complex words raises the important question of how morpheme position is repre- sented within the word recognition system. If words are recognized on the basis of their constituent morphemes, overhang can be distinguished from hangover only by the order in which their morphemes appear. Similarly, accepting dislike as an existing word while rejecting likedis as a nonword is a decision that must be based on morpheme position. This problem has remained almost totally ignored in the empirical literature on morphological processing, and current theoretical approaches to modeling the recognition of morphologically complex words have nothing to say about this issue.

The present work begins to fill these gaps by investigating whether suffixes are represented in a position-specific manner. We used the well-known morpheme interference effect (e.g., Caramazza et al., 1988; Taft \& Forster, 1975) as a behavioral diagnostic of the activation of suffix representations in visual word recognition. Consistent with previous research, results showed robust morpheme interference effects when morphologically structured nonwords were presented in their usual manner (e.g., gasful vs. gasfil), implicating the activation of morphemic suffix representations. However, these morpheme interference effects were totally absent when nonwords were presented with their morphemes reversed (e.g., fulgas vs. filgas), a situation that persisted even when the morpheme-reversed stimuli constituted actual words when presented in their usual manner (e.g., nesskind). These data suggest that morphemic suffix representations are position specific; they cannot be activated when suffixes are presented in the word-initial position.

Our findings place important constraints on the further development of theories of morphological processing. On the one hand, it seems clear that morphemic stem representations must be position invariant; if they were not, readers would be unable to recognize the connection between novel morphemic combinations like unheat and existing words like heating. Furthermore, it would be difficult to explain morphological priming results in which stems shared by the prime and target do not occupy the same position (e.g., review-VIEW or reward-WARD; see Feldman, Barac-Cikoja, \& Kostić, 2002, for relevant findings in Serbian). On the other hand, however, our data seem to demand that morphemic suffix representations (and presumably, morphemic prefix representations) must be position specific; if they were position invariant, we should have observed an interference effect for morpheme-reversed stimuli.

One possible speculation is that some form of position specificity is desirable in the representation of suffixes so as to avoid some automatic decompositions that would interfere with word identification. For example, although it may be helpful to automatically strip word endings like er in words like waiter (and such a strategy may also lead to the inappropriate segmentation of pseudosuffixed words like brother; e.g., Rastle et al., 2004), it would never be appropriate to strip er from the beginning of words like error or ergo. By extension, although the present evidence is restricted to suffixes, one might expect that prefixes can be stripped from word beginnings but not word endings (e.g., from misplace but not from salamis). It seems plausible 
that the introduction of such positional constraints would enable a putative affix-stripping mechanism to operate more efficiently without unduly increasing its complexity or capacity for rapid automatic decomposition of morphologically complex words.

\section{AUTHOR NOTE}

The present work was carried out at the Department of Psychology, Royal Holloway, University of London, where the first author was holding a postdoctoral fellowship granted by the Economic and Social Research Council, U.K. (PTA-026-27-1825). We gratefully acknowledge the contribution of research grants from the Leverhulme Trust (F/07 537/ $\mathrm{AB}$ ), the British Academy (SG-51566), and the ESRC (RES-000-223354). We also thank Sebastian Loth for his assistance in the selection of the orthographically unusual filler words in Experiment 2. Correspondence concerning this article should be addressed to D. Crepaldi, Dipartimento di Psicologia, Università di Milano-Bicocca, Piazza dell'Ateneo Nuovo 1, 20126, Milan, Italy (e-mail: davide.crepaldi1@unimib.it).

\section{REFERENCES}

Baayen, R. H., Dijkstra, T., \& Schreuder, R. (1997). Singulars and plurals in Dutch: Evidence for a parallel dual-route model. Journal of Memory \& Language, 37, 94-117. doi:10.1006/jmla.1997.2509

BRADLEY, D. (1980). Lexical representation of derivational relation. In M. Aronoff \& M.-L. Kean (Eds.), Juncture: A collection of original papers (pp. 37-55). Saratoga, CA: Anma Libri.

Caramazza, A., Laudanna, A., \& Romani, C. (1988). Lexical access and inflectional morphology. Cognition, 28, 297-332. doi:10.1016/ 0010-0277(88)90017-0

DAvis, C. J. (2006). Orthographic input coding: A review of behavioural data and current models. In S. Andrews (Ed.), From inkmarks to ideas: Current issues in lexical processing (pp. 180-206). Hove, U.K.: Psychology Press.

Davis, C. J., \& Bowers, J. S. (2006). Contrasting five different theories of letter position coding: Evidence from orthographic similarity effects. Journal of Experimental Psychology: Human Perception \& Performance, 32, 535-557.

Drews, E., \& Zwitserlood, P. (1995). Morphological and orthographic similarity in visual word recognition. Journal of Experimental Psychology: Human Perception \& Performance, 21, 1098-1116. doi:10.1037/0096-1523.21.5.1098

Feldman, L. B., Barac-Cikoja, D., \& Kostić, A. (2002). Semantic aspects of morphological processing: Transparency effects in Serbian. Memory \& Cognition, 30, 629-636.

Forster, K. I., \& Forster, J. C. (2003). DMDX: A Windows display program with millisecond accuracy. Behavior Research Methods, Instruments, \& Computers, 35, 116-124.

Giraudo, H., \& Grainger, J. (2001). Priming complex words: Evidence for supralexical representation of morphology. Psychonomic Bulletin \& Review, 8, 127-131.

Grainger, J. (2008). Cracking the orthographic code: An introduction. Language \& Cognitive Processes, 23, 1-35. doi:10.1080/ 01690960701578013

Grainger, J., Colé, P., \& Segui, J. (1991). Masked morphological priming in visual word recognition. Journal of Memory \& Language, 30, 370-384. doi:10.1016/0749-596X(91)90042-I

Grainger, J., \& Whitney, C. (2004). Does the huamn mnid raed wrods as a wlohe? Trends in Cognitive Sciences, 8, 58-59. doi:10.1016/ j.tics.2003.11.006

KaZanina, N., Dukova-Zheleva, G., Geber, D., Kharlamov, V., \& Tonciulescu, K. (2008). Decomposition into multiple morphemes during lexical access: A masked priming study of Russian nouns. Language \& Cognitive Processes, 23, 800-823. doi:10.1080/ 01690960701799635

Longtin, C.-M., Segui, J., \& Hallé, P. A. (2003). Morphological priming without morphological relationship. Language \& Cognitive Processes, 18, 313-334. doi:10.1080/01690960244000036

Marslen-Wilson, W. D., Bozic, M., \& Randall, B. (2008). Early decomposition in visual word recognition: Dissociating morphology, form, and meaning. Language \& Cognitive Processes, 23, 394-421. doi:10.1080/01690960701588004

New, B., Brysbaert, M., Segui, J., Ferrand, L., \& Rastle, K. (2004). The processing of singular and plural nouns in French and English. Journal of Memory \& Language, 51, 568-585. doi:10.1016/j.jml.2004 .06 .010

Perea, M., \& LuPKer, S. J. (2003). Transposed-letter confusability effects in masked form priming. In S. Kinoshita \& S. J. Lupker (Eds.), Masked priming: State of the art (pp. 97-120). Hove, U.K.: Psychology Press.

Rastle, K., Davis, M. H., Marslen-Wilson, W. D., \& Tyler, L. K. (2000). Morphological and semantic effects in visual word recognition: A time-course study. Language \& Cognitive Processes, 15, $507-$ 537. doi:10.1080/01690960050119689

Rastle, K., Davis, M. H., \& New, B. (2004). The broth in my brother's brothel: Morpho-orthographic segmentation in visual word recognition. Psychonomic Bulletin \& Review, 11, 1090-1098.

Shoolman, N., \& ANDREws, S. (2003). Racehorses, reindeer, and sparrows: Using masked priming to investigate morphological influences on compound word identification. In S. Kinoshita \& S. J. Lupker (Eds.), Masked priming: The state of the art (pp. 241-278). New York: Psychology Press.

TAFT, M. (1985). The decoding of words in lexical access: A review of the morphographic approach. In D. Besner, T. G. Waller, \& G. E. MacKinnon (Eds.), Reading research: Advances in theory and practice (pp. 83-126). New York: Academic Press.

TAFT, M. (1994). Interactive-activation as a framework for understanding morphological processing. Language \& Cognitive Processes, 9 , 271-294.

TAFT, M., \& Forster, K. I. (1975). Lexical storage and retrieval of prefixed words. Journal of Verbal Learning \& Verbal Behavior, 14, 638-647. doi:10.1016/S0022-5371(75)80051-X

TAFt, M., ZHU, X., \& Peng, D. (1999). Positional specificity of radicals in Chinese character recognition. Journal of Memory \& Language, 40, 498-519. doi:10.1006/jmla.1998.2625

UlRich, R., \& MilleR, J. (1994). Effects of truncation on reaction time analysis. Journal of Experimental Psychology: General, 123, 34-80. doi:10.1037/0096-3445.123.1.34

Yarkoni, T., Balota, D., \& Yap, M. (2008). Moving beyond Coltheart's $N$ : A new measure of orthographic similarity. Psychonomic Bulletin \& Review, 15, 971-979. doi:10.3758/PBR.15.5.971

\section{NOTE}

1. As in Experiment 1, post hoc analyses were conducted to test whether the results varied depending on whether the control-plus-stem nonwords began with a (pseudo)morphological unit (e.g., adytrip) or not (e.g., filgas). In neither case was there any sign of an interference effect in the reversed-morpheme conditions. 
APPENDIX A

Target Nonwords Used in Experiment 1

\begin{tabular}{|c|c|c|c|}
\hline Stem-Plus-Suffix & Stem-Plus-Control & Suffix-Plus-Stem & Control-Plus-Stem \\
\hline towerly & towerla & lytower & latower \\
\hline mudly & mudla & lymud & lamud \\
\hline nutly & nutla & lynut & lanut \\
\hline jawly & jawla & lyjaw & lajaw \\
\hline sheeter & sheetel & ersheet & elsheet \\
\hline beerer & beerel & erbeer & elbeer \\
\hline socketer & socketel & ersocket & elsocket \\
\hline figer & figel & erfig & elfig \\
\hline passment & passmant & mentpass & mantpass \\
\hline opposement & opposemant & mentoppose & mantoppose \\
\hline shootment & shootmant & mentshoot & mantshoot \\
\hline addment & addmant & mentadd & mantadd \\
\hline curtity & curtidy & itycurt & idycurt \\
\hline dumbity & dumbidy & itydumb & idydumb \\
\hline coldity & coldidy & itycold & idycold \\
\hline poority & pooridy & itypoor & idypoor \\
\hline heiric & heirig & icheir & igheir \\
\hline habitic & habitig & ichabit & ighabit \\
\hline altaric & altarig & icaltar & igaltar \\
\hline aidic & aidig & icaid & igaid \\
\hline begence & begenge & encebeg & engebeg \\
\hline ripence & ripenge & encerip & engerip \\
\hline flitence & flitenge & enceflit & engeflit \\
\hline pickence & pickenge & encepick & engepick \\
\hline gasful & gasfil & fulgas & filgas \\
\hline gumful & gumfil & fulgum & filgum \\
\hline taxful & taxfil & fultax & filtax \\
\hline fanful & fanfil & fulfan & filfan \\
\hline helmetous & helmetoes & oushelmet & oeshelmet \\
\hline fellowous & fellowoes & ousfellow & oesfellow \\
\hline boltous & boltoes & ousbolt & oesbolt \\
\hline classous & classoes & ousclass & oesclass \\
\hline freeness & freenels & nessfree & nelsfree \\
\hline trueness & truenels & nesstrue & nelstrue \\
\hline longness & longnels & nesslong & nelslong \\
\hline nextness & nextnels & nessnext & nelsnext \\
\hline meltance & meltange & ancemelt & angemelt \\
\hline happenance & happenange & ancehappen & angehappen \\
\hline prayance & prayange & ancepray & angepray \\
\hline stirance & stirange & ancestir & angestir \\
\hline inkism & inkilm & ismink & ilmink \\
\hline aridism & aridilm & ismarid & ilmarid \\
\hline antism & antilm & ismant & ilmant \\
\hline elbowism & elbowilm & ismelbow & ilmelbow \\
\hline earist & earilt & istear & iltear \\
\hline illist & illilt & istill & iltill \\
\hline urnist & urnilt & isturn & ilturn \\
\hline elmist & elmilt & istelm & iltelm \\
\hline tripary & tripady & arytrip & adytrip \\
\hline bogary & bogady & arybog & adybog \\
\hline lidary & lidady & arylid & adylid \\
\hline bandary & bandady & aryband & adyband \\
\hline rampize & rampime & izeramp & imeramp \\
\hline pillize & pillime & izepill & imepill \\
\hline treasonize & treasonime & izetreason & imetreason \\
\hline mouthize & mouthime & izemouth & imemouth \\
\hline digory & digody & orydig & odydig \\
\hline baskory & baskody & orybask & odybask \\
\hline flipory & flipody & oryflip & odyflip \\
\hline warnory & warnody & orywarn & odywarn \\
\hline witchish & witchith & ishwitch & ithwitch \\
\hline angelish & angelith & ishangel & ithangel \\
\hline beanish & beanith & ishbean & ithbean \\
\hline wigish & wigith & ishwig & ithwig \\
\hline
\end{tabular}


APPENDIX B

Simple Filler Words Used in Experiment 2

Topaz; hyena; koala; sphinx; larynx; zodiac; vortex; thorax; zombie; embryo; coyote; algebra; dilemma; academy; rhubarb; episode; synonym; nirvana; paradox; jubilee; sarcasm; turmoil; pilgrim; hygiene; diploma; scenario; protocol; panorama; volcano; platypus; nicotine; appendix; skeleton; evacuate; delirium; epilogue; euphoria; synopsis; kangaroo; souvenir; anecdote; linoleum; dinosaur; crucifix; kamikaze; daffodil; dyslexia; innuendo; petroleum; barracuda; crocodile; pneumonia; gymnasium; apocalypse; eucalyptus; rhinoceros.

APPENDIX C

Target Nonwords Used in Experiment 3

\begin{tabular}{|c|c|c|c|}
\hline TM & TM Control & TH & TH Control \\
\hline lysteep & gysteep & trethea & trothea \\
\hline lymere & gymere & iffsher & effsher \\
\hline erteach & urteach & turecul & tarecul \\
\hline ersell & ursell & relquar & ralquar \\
\hline mentbase & mirtbase & tateagi & tafeagi \\
\hline mentpunish & mirtpunish & tudeatti & tadeatti \\
\hline itycomplex & ibycomplex & glestrug & glastrug \\
\hline ityvalid & ibyvalid & settecas & sattecas \\
\hline icarab & ocarab & trastcon & tristcon \\
\hline icperiod & ocperiod & sisempha & fisempha \\
\hline encediffer & engediffer & cretecon & clitecon \\
\hline encerefer & engerefer & thysympa & physympa \\
\hline fulfaith & falfaith & loguedia & lothedia \\
\hline fulcheer & falcheer & traitpor & troitpor \\
\hline oushazard & oashazard & ulesched & ilesched \\
\hline ousdanger & oasdanger & laumbrel & taumbrel \\
\hline nessdeaf & nelsdeaf & mercecom & merpecom \\
\hline nesswit & nelswit & thonmara & thunmara \\
\hline anceassist & angeassist & tainfoun & tuinfoun \\
\hline anceperform & angeperform & rangueha & rangleha \\
\hline ismego & irmego & quentfre & quintfre \\
\hline ismalcohol & irmalcohol & tiquecri & tishecri \\
\hline istart & irtart & lainchap & loonchap \\
\hline istunion & irtunion & relsquir & rulsquir \\
\hline arydiet & alydiet & rioncrite & liancrite \\
\hline arycustom & alycustom & lengechal & langechal \\
\hline izecritic & ifecritic & niquetech & noquetech \\
\hline izereal & ifereal & teeguaran & taeguaran \\
\hline ifynull & igynull & bourneigh & bairneigh \\
\hline ifyfort & igyfort & susconsen & sisconsen \\
\hline orydirect & otydirect & latechoco & litechoco \\
\hline orytransit & otytransit & oldthresh & eldthresh \\
\hline ishwarm & iphwarm & taclespec & tuclespec \\
\hline ishfool & iphfool & ricanehur & rolanehur \\
\hline
\end{tabular}

Note-TM, transposed morpheme; TH, transposed halves.

(Manuscript received June 4, 2009;

revision accepted for publication September 14, 2009.) 